SHS Web of Conferences 2, 00024 (2012)

DOI: $10.1051 /$ shsconf/20120200024

(C) Owned by the authors, published by EDP Sciences, 2012

\title{
Study of accessibility and quality of the patient information about medicines in Latvia
}

\author{
V. Ozolina
}

Rīga Stradinsš University, Latvia

\begin{abstract}
Receipt of adequate amount of accurate patient information on medicines before their use is one of the main cornerstones of the treatment. Without the information medicines cannot be used safely and effectively. Basically, it can be argued that the information is converting the pharmacologically active substance into the medicinal product. Main source of information for patients in Latvia is Package leaflets. Label of medicines and patient information leaflet are drawn up in compliance with regulatory requirements, but for people it is often difficult to understand information contained in the package leaflets due to the complex language. The readability test - introduced as a mandatory requirement for marketing authorization and renewal of marketing authorization of medicines - improves the quality of package leaflets making them more patient "friendly".
\end{abstract}

Key words: medicines, patient information leaflet, pharmaceutical care

Rapid development of the world determines also increased effects from medicines on the human health. Medicines affect and change health status and quality of life; human health and even life depends upon them.

A man has the right to receive information on his/her disease, treatment, and on the medicines he/she is taking. Nowadays, the information on diseases, treatments and medicines can be collected not only at the doctor or pharmacist, but it is also widely available in the public environment: publications, on the internet. At present, the problem is not to receive the information, but how to find and get the most essential, objective and valuable things in the set of data and news (Kichbusch, 2007).

One of the basic functions of the pharmacist's activities is the consultation of pharmacy's clients (patients) on medicines, their use, and the monitoring of the self-treatment.

\section{The aim of the study}

To explore the availability of the information about the medicines to patients in Latvia, particularly focusing on the package leaflet analysis, evaluating their compliance with legislative requirements, and apprehensibility for people.

In order to reach the aim the following tasks have been proposed:

1) To explore and describe what information about medicines is needed and available to patients.

2) To consider and analyse the key requirements set by the legislative acts for medicine labels and package leaflets.

3) To perform analyses of the pharmacy customers' questionnaires on the quality of package leaflets in Latvia and to evaluate the results.

This is an Open Access article distributed under the terms of the Creative Commons Attribution License 2.0, which permits unrestricted use, distribution, and reproduction in any medium, provided the original work is properly cited. 


\section{SHS Web of Conferences}

\section{Materials and methods}

As the theoretical and methodological basis for the study, information collected from the foreign and local press, the State Agency of Medicines' materials, and the internet resources were used. In order to reach the defined aim and solve the proposed tasks, several study methods were used:

- referative analysis: theoretical analysis of the literature in order to establish the theoretical positions on the availability and quality of the information on medicines;

- survey method: questionnaires by interviewing patients and receiving replies on questions in a definite sequence.

In the questionnaires, the following was noted:

- characteristics of the medicine user (gender, sex, education);

- do people read package leaflets;

- do they understand the content of package leaflets;

- what information sources on medicines do people use;

- other questions that allow to evaluate the patient's level of awareness.

The data collected in the form of questionnaires were used; visitors at 75 Latvian pharmacies aged 20 to 80 years were interviewed. $63 \%$ of respondents were females, $37 \%$ were males.

Study period: years 2009 to 2010. For the data statistical treatment, MS Excel software was used.

\section{Results}

In the modern evidence based medicine, drugs are one of the treatment components. More and more people take medicines to improve and preserve their health. Very commonly, the over-thecounter medicines are the ones chosen to alleviate different complaints and symptoms. The evidence are the medicines consumption statistical data published by the State Agency of Medicines. In $2008,62 \%$ of packages sold in pharmacies were prescription medicines, but $48 \%$ over-the-counter medicines.

When choosing the pharmacological therapy, it is important for the man to know what exactly the prescribed medicine is, and to receive additional information on the drug, their use, if an over-thecounter medicine has been purchased. The information intended for the user has to be eligible and shall correspond to the local legislation. It is important that the written text is understandable for lay persons. Different populations need different kind of medical information.

\section{Requirements for the medicines labelling}

Information on the medicines include: information on the package, package leaflet and the summary of product characteristics. Requirement for the medicines labelling are provided in the LR Cabinet of Ministers Regulation on the procedure for the medicines labelling and requirements for package leaflets developed according to the EMA (European Medicines Agency) guidelines.

Information in the labelling on the primary packaging of the medicine (in direct contact with the drug) and the secondary packaging (where the primary packaging is inserted), and the information in the package leaflet is given according to provisions of the Law on the State Language, i.e. it should be in Latvian.

Package leaflet is the set of information on the medicine: its contents, usage, side effects, storage and other important and essential facts which should be known about the definite medicine. The package leaflet is also a kind of safety rendering to the patient: one does not have to remember everything discussed with the pharmacist, since he/she will be able to re-read the leaflet text at home, and refer to it each time according to the need. Therefore, it is very important for the manufacturers of the over-thecounter medicines to develop a good package leaflet text. 


\section{Int. Conf. SOCIETY. HEALTH. WELFARE; Congr. of Rehabilitation Doctors of Latvia}

\section{Package leaflet readability}

One of the main essential characteristics of package leaflets is their readability. European Commission readability guidelines have been developed to help to ensure readability of package leaflets, so that the administration of medicines is safe and adequate.

Regulations provided in the readability guidelines are mandatory both for prescription and over-thecounter medicines. Package leaflets are intended for the user, and it should be well designed, literary composed correctly, eligible also for young people, individuals with vision problems and users without relevant medical education (European Advertising Standards Alliance, 1997).

The main discussed and recommended topics of the guidelines are:

1) Character size and font size.

2) Arrangement of the information.

Spacing between lines is important to improve the readability of the text. There should be a contrast between the colour of characters and the background to improve the comprehension of the information. Factors like the colour of the paper, its weight and size should be considered as well.

3) Titles.

These are very important since they help the reader to glance over the main components of the package leaflet contents.

4) Choice of the colour.

For readability, not only the character size, but also the colour is of importance. Various colours can be used, since additional contrast highlights the most essential information. The basis of the text should be in a light colouring.

5) Syntax.

6) The text should be composed in a maximum simple and easy-to-read way, considering users with low language and literary expression skills. Sentences should be sufficiently short, thus improving the understanding of the information.

7) Writing style.

Medical terms should be written in a wording understandable for the user. Acronyms are not recommended.

8) Paper.

The paper should not be very thin, shiny, since this may affect the readability.

9) The use of symbols and pictograms.

Figures, pictograms and other graphical pictures are allowed, unless intended for advertising purposes (European Commission, 2008).

\section{Questionnaire results}

Results of the questionnaire show that the information on medicines is widely available in Latvia. More and more people, $64 \%$ of respondents, use internet data bases to get the information, however, within the scope of the study, we focused on the analysis of package leaflets and their role as the source of information. One of questions was whether people are reading patient information leaflets (see Figure 1).

$61 \%$ of respondents gave affirmative answer. Replies of $18 \%$ were negative, and $21 \%$ noted that they read package leaflets sometimes. This gives the message that people are interested in what they are 
Do you read package leaflets?

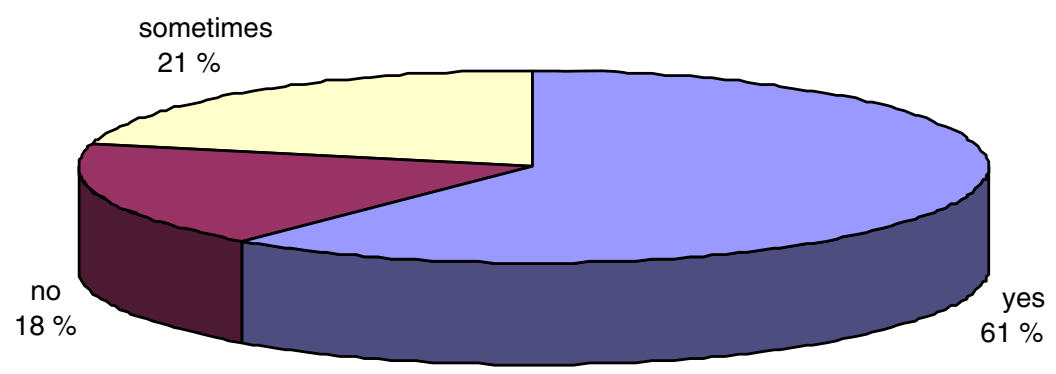

Figure 1.

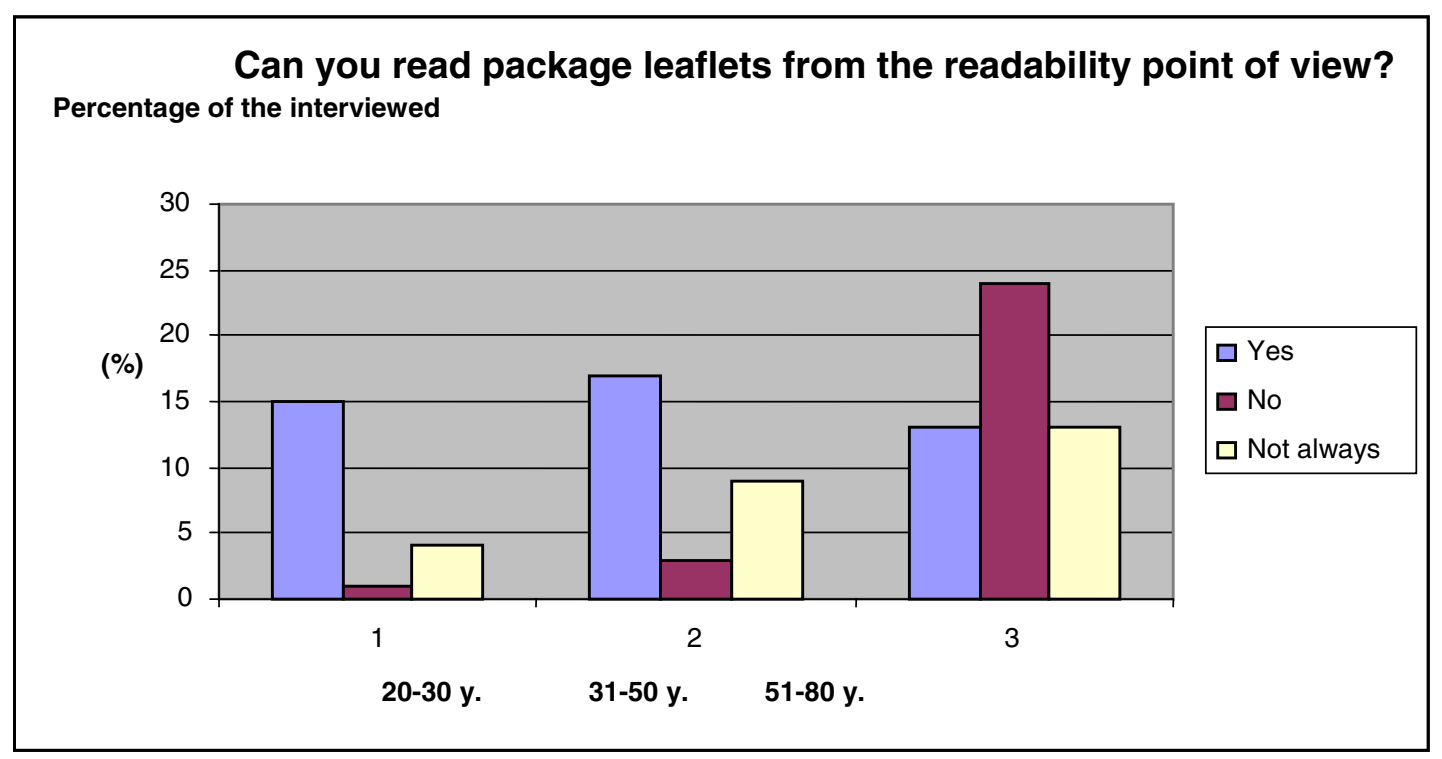

Figure 2.

using. It is a very positive fact, since people do not only take advertisements for a gospel truth, but also want themselves to get information or assure that the pharmacist consultation has been correct.

One of the problems that people face when reading package leaflets is the readability. Many individuals, particularly elderly, have difficulties to read the written text, because the letter size is too small in their opinion (see Figure 2).

One of the questions in the questionnaire that was asked people was whether they understand the content of the leaflet. Commonly, package leaflets are very "saturated" with various complicated medical terms that are hardly understandable and interpreted in various ways. Readability of package leaflets for the over-the-counter and prescription medicines was evaluated separately. Results show that package 
Int. Conf. SOCIETY. HEALTH. WELFARE; Congr. of Rehabilitation Doctors of Latvia

Table 1. Do you understand the content of the package leaflets?

\begin{tabular}{lcc}
\hline & $\begin{array}{c}\text { Package leaflets for } \\
\text { over-the-counter medicines }\end{array}$ & $\begin{array}{c}\text { Package leaflets for } \\
\text { prescription medicines }\end{array}$ \\
\hline Yes & $68 \%$ & $41 \%$ \\
\hline No & $12 \%$ & $27 \%$ \\
\hline Not always & $20 \%$ & $32 \%$ \\
\hline
\end{tabular}

\section{Patients' activities when the medicine has been bought for the first time}

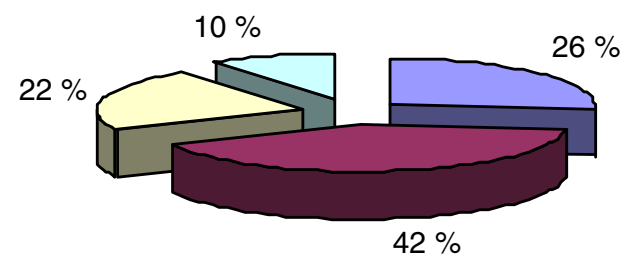

$\square$ Read and keep the PI

$\square$ Read and dispose of the PI

Do not read the PI, receive $\square$ the information from the doctor and pharmacist

\section{$\square$ Use the information on the outer labelling}

Figure 3.

leaflets for prescription medicines are more difficult to understand. Some of the most common reasons mentioned why leaflets are not easily understandable are as follows:

- complicated language;

- medical terms;

- lack of the Latvian language knowledge.

$68 \%$ of respondents recognized that package leaflets for over-the-counter medicines are easier to understand, but package leaflets for prescription medicines were easily understandable for $41 \%$ of the interviewed (see Table 1).

$42 \%$ of respondents do read package leaflets and then dispose of them, $26 \%$ of respondents read the package leaflet when they buy the medicine for the first time, and keep them to re-read, when needed. However, $22 \%$ of people recognized that they do not read package leaflets, since they follow the information given by the doctor and pharmacist, and $10 \%$ of respondents use the information available on the outer labelling (see Figure 3).

$33 \%$ of respondents stated that to obtain information on medicines they read package leaflets, $29 \%$ of respondents use information that can be found in the internet data bases, $23 \%$ - in press, $11 \%$ obtain information from different advertisement booklets, brochures, 9\% - use outer packaging of medicinal products to obtain information (see Figure 4).

$61 \%$ of respondents recognized that the information on medicines available to them is sufficient, $32 \%$ said the information is not always sufficient, but $7 \%$ of respondents were not satisfied with the amount of the available information on medicines (see Figure 5). 


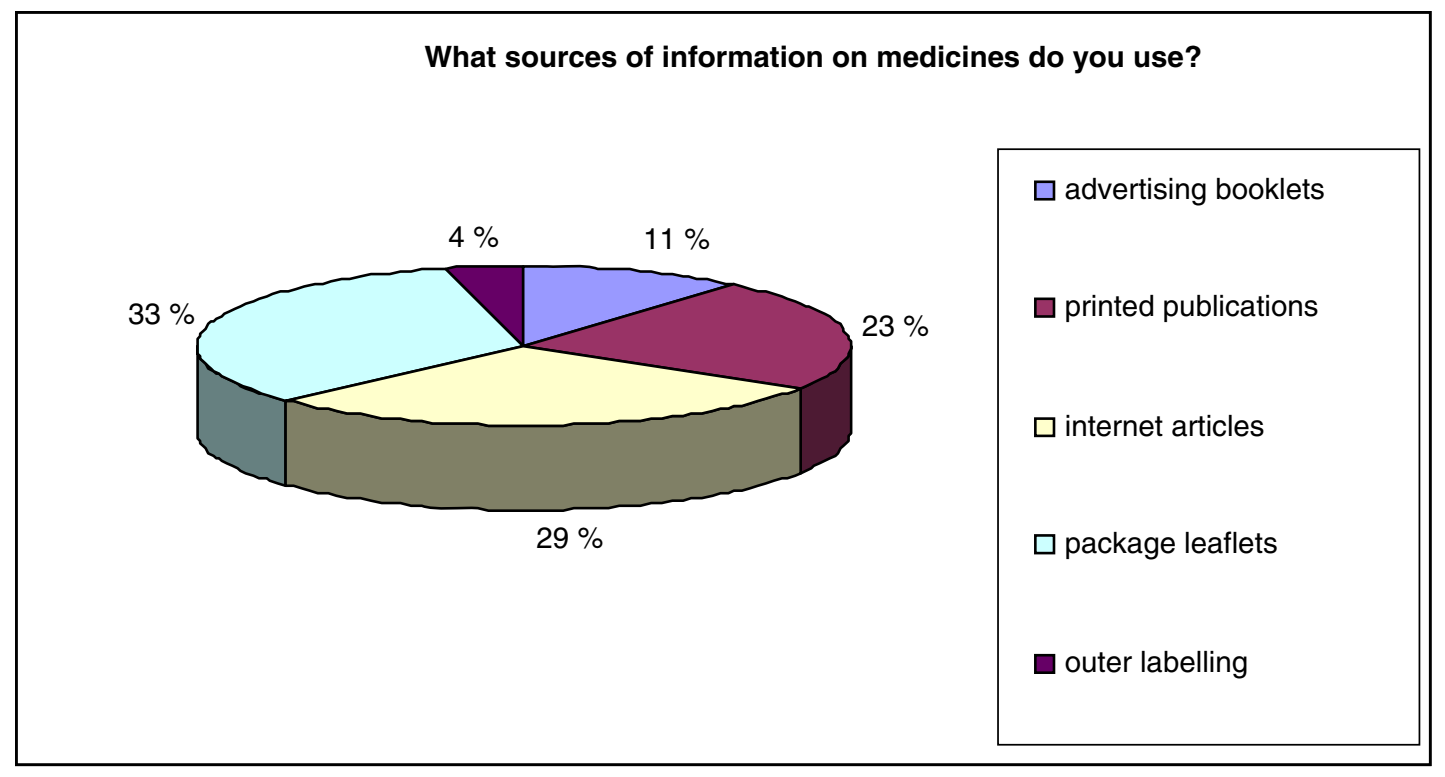

Figure 4.

\section{Is the available information on medicines sufficient?}

not always sufficient

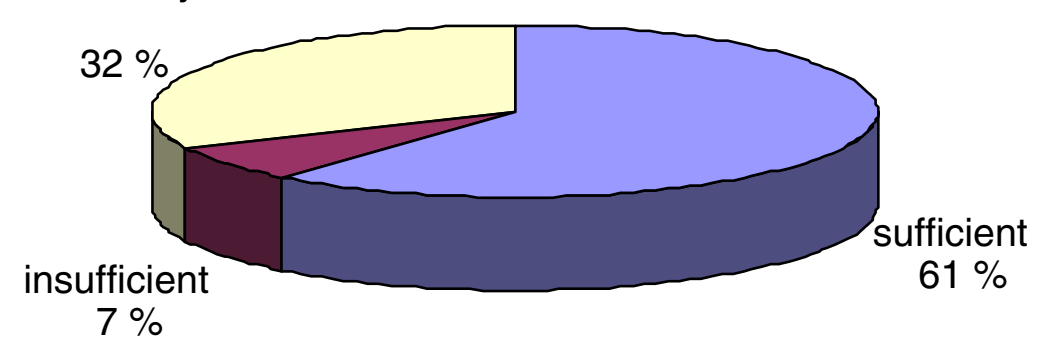

Figure 5.

\section{Discussion}

Any information intended for a patient should be simple and understandable, safe and verified, ethical and unobtrusive. Only in such cases we do accept it and are ready to assess it, and use it in specific cases. This is particularly important for medicines, since inaccurate, misleading information or information that encourages an excessive use of medicines can have very pitiful consequences for patients. According to principles of qualitative pharmaceutical care, user consultation on medicines is 


\section{Int. Conf. SOCIETY. HEALTH. WELFARE; Congr. of Rehabilitation Doctors of Latvia}

one of the essential components a pharmacist faces in his/her routine work. Pharmacist uses his/her knowledge to inform clients on the use, compatibility of medicines and their effects.

The role of the pharmacist in the process of giving information is extremely important: he/she should provide both an oral consultation, and explain and help to understand correctly the information the patient has found in different sources. One should also advise on reliable literature sources providing objective information. It is of great importance to find a common language with the patient and perform an explanatory work in a language understandable to him/her. The pharmacist should not provide inconsistent information, because it may confuse the patient.

Dispensed medicines should be labelled according to the provisions of the legislation on labelling and package leaflets. Any information promoting the use of medicines is a subject to strict regulations and approval procedures in the European Union and elsewhere in the world. Therefore, information/advertisements intended for specialists is being precisely separated the one provided for the society. The law provides both the responsibility of both the advertiser and the distributor of the advertisement. Ethical aspects have an essential role.

Written sources of information about medicines available for patients in Latvia are the following:

- Different advertisement brochures of medicines.

- Newspapers, magazines.

- Information on the Internet.

- Drug labeling and package leaflets.

Sufficient and correct information on medicines to the patient before their use is one of the self-treatment cornerstones. Without information, medicines cannot be used safely and effectively. Information gives the best results, when prepared personally for a specific individual, therefore, it could be more effective than the printed materials (Kichbusch I, 2007).

\section{Conclusions}

1. The information about medicines in written form, which is intended for patients: a) is necessary b) is broad, but not necessarily well understandable, and therefore does not always result in an adequate medicine administration.

2. The information about medicines on the Internet and in press is mostly advertising and for the patient without medical education it is difficult to asses it.

3. Package leaflets available in Latvia and drug labels are drawn up in compliance with regulatory requirements, but for people it is often difficult to understand information contained in the package leaflets due to the complex language.

4. The readability test - introduced as a mandatory requirement for marketing authorization and renewal of marketing authorization of medicines - improves the quality of package leaflets making them more patient 'friendly'.

5. One very important criterion for the quality of package leaflet is a letter size, and printing, it is particularly topical for patients after 50 years of age.

6. The pharmacist has an essential, indispensable role in informing the patient - providing and explaining information on the medicines within the framework of the pharmaceutical care.

\section{References}

[1] Kichbusch, I. Enabling healthy choices in modern health societies. 8th European Health Forum. Austria, Bad Gastein, 2007.

[2] Eiropas pasūtījuma darbs. Veselība Eiropas Savienībā. Eiropas komisija.

[3] European Advertising Standarts Alliance, Advertising Self-Regulation in Europe Medicine Advertising regulation and Self-Regulation in 54 countries. Belgium, Brussels, 1997. 